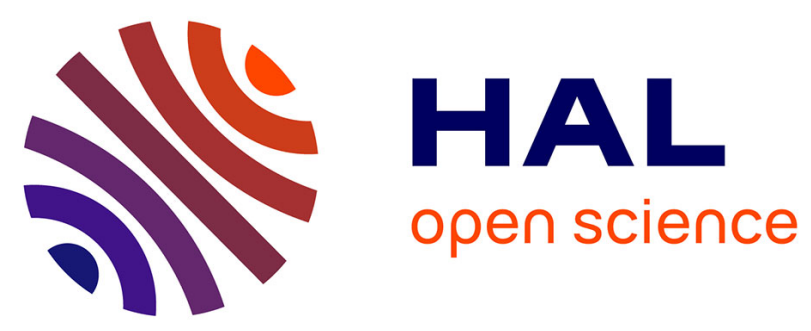

\title{
A new characterization approach for studying relationships between microstructure and creep damage mechanisms of uranium dioxide
}

X. Iltis, M. Ben Saada, H. Mansour, N. Gey, Alain Hazotte, Nabila Maloufi

\section{- To cite this version:}

X. Iltis, M. Ben Saada, H. Mansour, N. Gey, Alain Hazotte, et al.. A new characterization approach for studying relationships between microstructure and creep damage mechanisms of uranium dioxide. Journal of Nuclear Materials, 2016, 474, pp.1-7. 10.1016/j.jnucmat.2016.02.027 · cea-02382809

\section{HAL Id: cea-02382809 https://hal-cea.archives-ouvertes.fr/cea-02382809}

Submitted on 9 Dec 2019

HAL is a multi-disciplinary open access archive for the deposit and dissemination of scientific research documents, whether they are published or not. The documents may come from teaching and research institutions in France or abroad, or from public or private research centers.
L'archive ouverte pluridisciplinaire HAL, est destinée au dépôt et à la diffusion de documents scientifiques de niveau recherche, publiés ou non, émanant des établissements d'enseignement et de recherche français ou étrangers, des laboratoires publics ou privés. 


\title{
A new characterization approach for studying relationships between microstructure and creep damage mechanisms of uranium dioxide
}

\author{
X. Iltis ${ }^{\text {a, }}{ }^{*}$, M. Ben Saada ${ }^{\text {a, b }}$, H. Mansour ${ }^{b}$, N. Gey ${ }^{b}$, A. Hazotte ${ }^{b}$, N. Maloufi ${ }^{b}$ \\ ${ }^{a}$ CEA, DEN, DEC, Cadarache, 13108 Saint-Paul-Lez-Durance, France \\ ${ }^{\mathrm{b}}$ Laboratoire d'Etudes des Microstructures et de Mécanique des Matériaux (LEM3), CNRS UMR 7239, Université de Lorraine, Ile du Saulcy, 57045 Metz \\ Cedex 1, France
}

\section{H I G H L I G H T S}

- Four different $\mathrm{UO}_{2}$ pellets batches are microstructurally compared, before and after compression creep tests.

- Development of sub-boundaries within the original grains, in crept samples, is quantified by EBSD.

- Links are observed between the intra-granular pores population of the as-sintered samples, their creep rate and their sub-structured state, after mechanical tests.

\section{A R T I C L E I N F O}

\section{Keywords:}

Uranium dioxide

Creep

Microstructure

Porosity

SEM

EBSD

ECCI

\begin{abstract}
A B S T R A C T
Four batches of $\mathrm{UO}_{2}$ pellets were studied comparatively, before and after creep tests, to evaluate a characterization methodology aimed to determine the links between microstructure and damage mechanisms induced by compressive creep of uranium dioxide at $1500{ }^{\circ} \mathrm{C}$. They were observed by means of scanning electron microscopy (SEM) coupled with image analysis, to quantify their fabrication porosity and the occurrence of inter-granular cavities after creep, and electron back scattered diffraction (EBSD), especially to characterize sub-structures development associated with plastic deformation. Electron channeling contrast imaging (ECCI) was also applied to evidence dislocations, at an exploratory stage, on one of the deformed pellets.

This approach helped to identify and quantify microstructural differences between batches. Their asfabricated microstructures differed in terms of grain size and fabrication porosity distribution. The pellets which had the lowest strain rates were those with the largest number of intra-granular pores, regardless of their grain size. They also exhibited less numerous sub-boundaries within the grains.

These first results clearly illustrate the benefit of systematic examinations of crept $\mathrm{UO}_{2}$ pellets at a mesoscopic scale, by SEM and EBSD, to study their deformation process. In addition, ECCI appears as a powerful tool to evidence local dislocations arrangements, in bulk samples. Even if the sampling was limited, the results of this study also tend to indicate that the intra-granular pores population, resulting from the manufacturing of the samples by powder metallurgy, could have a significant influence on the $\mathrm{UO}_{2}$ viscoplastic deformation mechanisms.
\end{abstract}

\section{Introduction}

To improve the performances of the sintered uranium dioxide $\left(\mathrm{UO}_{2}\right)$ fuel commonly used in nuclear power plants, it is necessary to decrease the risk of rupture of the fuel rods by Pellet-Cladding Interaction (PCI). This phenomenon occurs during power

\footnotetext{
* Corresponding author.

E-mail address: xaviere.iltis@cea.fr (X. Iltis).
}

transients, which induce a significant temperature increase in the central part of the fuel pellets (from approximately $1000{ }^{\circ} \mathrm{C}$, to $1500{ }^{\circ} \mathrm{C}$ or even $2000{ }^{\circ} \mathrm{C}$, depending on the maximum power reached) [1-3]. This sharp temperature increase generates high stresses in the cladding due to the swelling of the pellet [4-6], and viscoplastic deformation mechanisms in the hottest part of the ceramic.

Over the past forty years, these mechanisms were mainly studied out of irradiation, by means of compressive creep tests, in 
different conditions of temperature and stress [7-13]. These previous studies were not systematically associated with fine microstructural examinations of crept samples. Moreover, when such examinations were carried out, they were mostly performed on thin foils, by transmission electron microscopy (TEM), that is on very limited areas (a few grains) [11,13]. Thus, despite these numerous studies, many questions remain open about the links between microstructural characteristics (grain size, pores distribution ...) and creep mechanisms, especially concerning subboundaries development in dislocational creep regime.

In order to try to get new clues about these links, we compare in this study four $\mathrm{UO}_{2}$ pellets batches with different microstructures in terms of grain size and porosity distribution. These pellets were submitted to compression creep tests at relatively high stress levels at $1500{ }^{\circ} \mathrm{C}$, performed up to mean deformations of the order of $8 \%$. Their microstructures were characterized before and after mechanical test, mainly by scanning electron microscopy (SEM), coupled with image analysis, and electron backscattered diffraction (EBSD), on the basis of a methodology that has been previously implemented on other $\mathrm{UO}_{2}$ samples [14]. The potential of this approach to determine quantified microstructural characteristics, before and especially after creep tests, is more particularly evaluated.

\section{Experimental}

\subsection{Materials}

Table 1 summarizes the main characteristics of the materials studied. They correspond to $\mathrm{UO}_{2}$ pellets, with a diameter of $8 \mathrm{~mm}$ and a height between 10 and $12 \mathrm{~mm}$ (dimensions before deformation), obtained by uniaxial pressing followed by natural sintering. Four different fabrication batches were used:

- two batches with relatively large grains, named LG1 and LG2 ( $\mathrm{LG}=$ Large Grains), with the same densities (and therefore the same total porosity).

- two batches with smaller grains, named SG1 and SG2 (SG = Small Grains), with relatively different densities.

Densities were measured by an immersion method. Grain sizes were measured by EBSD on surfaces of about $0.5 \mathrm{~mm}^{2}$, considering a $5^{\circ}$ critical disorientation angle for grain boundaries detection [14].

The first three batches (LG1, LG2, SG1) were manufactured in the $\mathrm{UO}_{2}$ Laboratory facility (CEA/Cadarache), from the same $\mathrm{UO}_{2}$ powder. A sintering under an atmosphere of $95 \% \mathrm{Ar}+5 \% \mathrm{H}_{2}$ was chosen to ensure the material stoichiometry. Their microstructural differences were obtained by varying the initial agglomeration rate of the powder and the sintering conditions (temperature: $1700{ }^{\circ} \mathrm{C}$ or $1900{ }^{\circ} \mathrm{C}$, duration: from 4 to $10 \mathrm{~h}$ ). The fourth batch (SG2), with small grain size and lower density, has been produced in an industrial installation, using another $\mathrm{UO}_{2}$ powder mixed with a pore former (AZB: azodicarbonamide).

\subsection{Creep tests}

Pellets from each batch were submitted to creep tests in uniaxial compression, under a $95 \% \mathrm{Ar}+5 \% \mathrm{H}_{2}$ atmosphere (to maintain the material stoichiometry during the test), and using the following conditions: $1500^{\circ} \mathrm{C}-50 \mathrm{MPa}$ for the coarse microstructures (LG1 and LG2), and $1500^{\circ} \mathrm{C}-70 \mathrm{MPa}$ for those with smaller grains (SG1 and SG2). These conditions were selected in order to activate mostly dislocational creep mechanisms, on the basis of previous studies [11,15-17], performed with the same mechanical testing device, on $\mathrm{UO}_{2}$ pellets with microstructures either identical (for LG1 and SG1) [15] or close (for LG2 and SG2) [11,15-17] to those considered in this work. Test durations were chosen to reach systematically an about $8 \%$ mean strain level, for which steady state creep conditions were achieved and pellets presented well developed sub-structures [11,15-17].

The contraction of the pellet was continuously measured during test, using two extensometers in contact with two tungsten endplates between which the pellet was blocked. At the end of the tests, the pellets were cooled at a relatively quick rate $\left(30^{\circ} \mathrm{C} / \mathrm{min}\right)$, under a low compression load (5 MPa). Complementary details concerning the testing machine characteristics and testing procedures are given in Refs. [11,15-18].

The crept pellets exhibited a more or less marked barrel shape after test, since friction occurred at their ends. They had very different mean strain rates: they varied from $0.7 \% /$ h for SG2 to $9.4 \% /$ $\mathrm{h}$ for SG1 (see Table 2). Such kinetic differences are consistent with those encountered in previous studies (in particular those from Refs. [11,15-17]), but cannot be compared in depth with them because only one testing condition was chosen per microstructure in this study (its aim being focused on the development of a comparative characterization methodology).

\subsection{Characterization methods}

A longitudinal cut (i.e. parallel to the compression direction) was performed with a diamond wire saw in the central part of the reference pellets (as sintered) and of the crept ones. The samples obtained after cutting were mechanically polished. To obtain a suitable surface state for EBSD and ECCI characterizations the final polishing step was performed with a $0.04 \mu \mathrm{m}$ silica aqueous solution. Polished samples were observed by scanning electron microscopy (SEM) in backscattered electrons (BSE) mode, using a FEI Nova NanoSEM 450 microscope for standard SEM imaging and EBSD characterizations, and a ZEISS AURIGA 40 microscope for examinations in ECCI conditions [19]. The characterization of

Table 2

Average strains and strain rates obtained for the four crept pellets.

\begin{tabular}{lll}
\hline Batch & Average strain (creep test duration) & Average strain rate $(\% / \mathrm{h})$ \\
\hline LG1 & $8 \%(3 \mathrm{~h})$ & 2.7 \\
LG2 & $6 \%(7 \mathrm{~h})$ & 0.9 \\
SG1 & $9.4 \%(1 \mathrm{~h})$ & 9.4 \\
SG2 & $8.8 \%(13 \mathrm{~h})$ & 0.7 \\
\hline
\end{tabular}

Table 1

Main characteristics of the studied batches.

\begin{tabular}{|c|c|c|c|}
\hline Batch & Sintering conditions (temperature, time) & Average grain size, in $\operatorname{ECD}^{\mathrm{a}}(\mu \mathrm{m})$ & $\%$ of the $\mathrm{UO}_{2}$ theoretical density \\
\hline LG1 & $1900{ }^{\circ} \mathrm{C}-4 \mathrm{~h}$ & 23 & 98.6 \\
\hline LG2 & $1900{ }^{\circ} \mathrm{C}-10 \mathrm{~h}$ & 21 & 98.6 \\
\hline SG1 & $1700{ }^{\circ} \mathrm{C}-4 \mathrm{~h}$ & 15 & 98.1 \\
\hline SG2 & $1700^{\circ} \mathrm{C}-4 \mathrm{~h}$ & 10 & 96.3 \\
\hline
\end{tabular}

${ }^{a}$ ECD: equivalent circular diameter, i.e. disk diameter of the same area as the grain. 
porosity in the as-manufactured reference samples was performed on surfaces of about $0.05 \mathrm{~mm}^{2}$ by image analysis, using the Olympus AnalySIS software. Taking into account the resolution (pixel size) of the images used for characterizing the reference samples porosity, only pores with Equivalent Circular Diameters (ECD) greater than $0.1 \mu \mathrm{m}$ were measured. In order to separate the pores in inter-granular positions (i.e. all pores in contact with grain boundaries) from those located in intra-granular positions, the grain boundary network was drawn on the electronic image using a graphic tablet and was then superimposed on the binarized image of the whole porosity (cf. Fig. 1).

To identify the most important creep damaged areas, the entire polished section of the crept pellets was examined by SEM. These areas were identified by the presence of inter-granular cavities and sub-grain boundaries, which densities varied depending on the sample, as it will be described later. They were not always located at the center of the pellet, as expected, probably because of slight positioning offsets in the testing machine and/or defects distribution heterogeneities at the pellet scale [20]. The effective deformation level reached in these areas is not determined (a mean deformation being only measured for the whole pellet) but it seems reasonable to assume, in first approximation, that this level is roughly the same in the four studied samples.

EBSD maps were performed on the most damaged area of each sample, on surfaces of about $1 \mathrm{~mm}^{2}$, by means of a Nano II Nordlys camera from Oxford Instruments (in $2 \times 2$ binning mode: $672 \times 512$ pixels) driven by the AZTEC software. The results obtained were analyzed using the software suite CHANNEL 5 (version 5.11). The indexing rate of EBSD data ranged between $92 \%$ and $98.5 \%$, depending on the number of pores and cavities present in the analyzed surfaces. The EBSD data acquisition and post-processing conditions allowed to detect accurately angular disorientations between two adjacent points of $0.5^{\circ}$ (or more). Thus, disorientation thresholds of $0.5^{\circ}$ and $5^{\circ}$ were respectively chosen to detect subgrain boundaries and grain boundaries on EBSD maps.

The sample deformed up to $8 \%$ (mean value) from the batch LG1 also underwent additional examinations by electron channeling contrast imaging (ECCI), using the methodology described by Mansour et al., which is based on a suitable orientation of the grain in order to be in two-beam conditions, and highlight the contrast associated with the presence of crystallographic defects [21,22].

\section{Results}

\subsection{Fabrication porosity in the as-sintered reference pellets}

The examination of the reference samples by SEM revealed homogeneous microstructures, with equiaxed grains and small inter- and intra-granular pores (Fig. 2a), typical of $\mathrm{UO}_{2}$ sintered
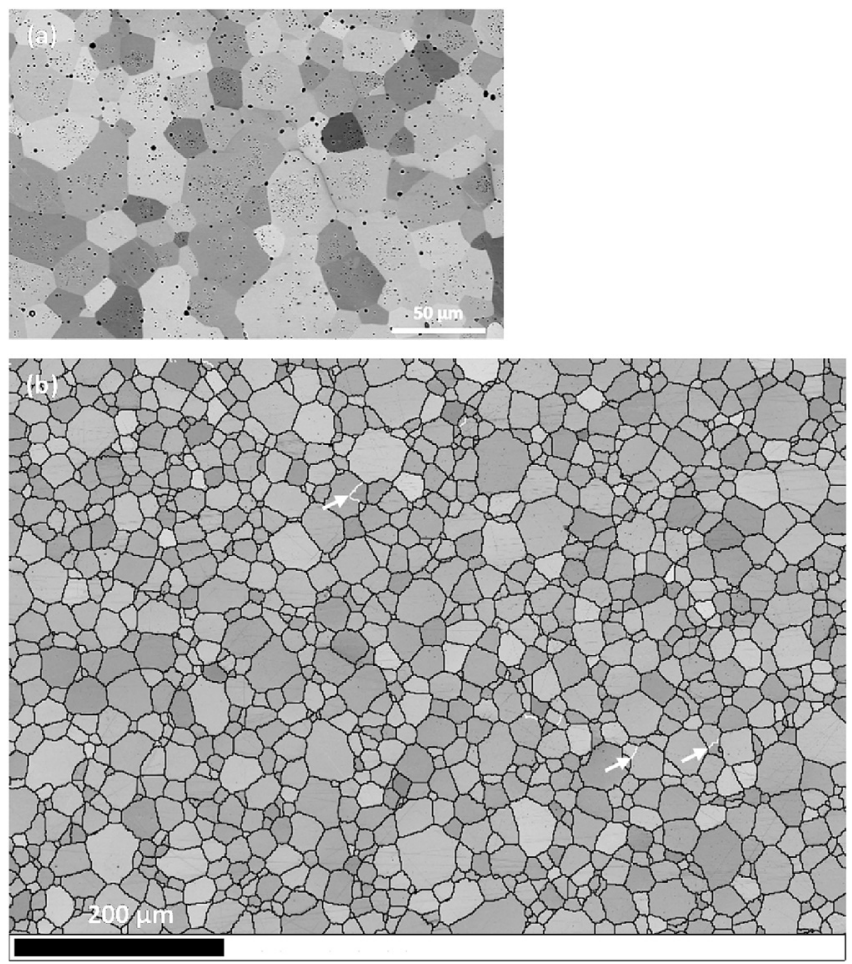

Fig. 2. (a) SEM micrograph (in back-scattered electrons mode) taken from the LG1 batch reference sample, (b) EBSD map obtained on this sample: Kikuchi pattern quality map, grain boundaries (black lines: disorientation $\geq 5^{\circ}$ ) and "sub-grain" boundaries (white lines: disorientation comprised between $0.5^{\circ}$ and $5^{\circ}$ ) are superimposed.
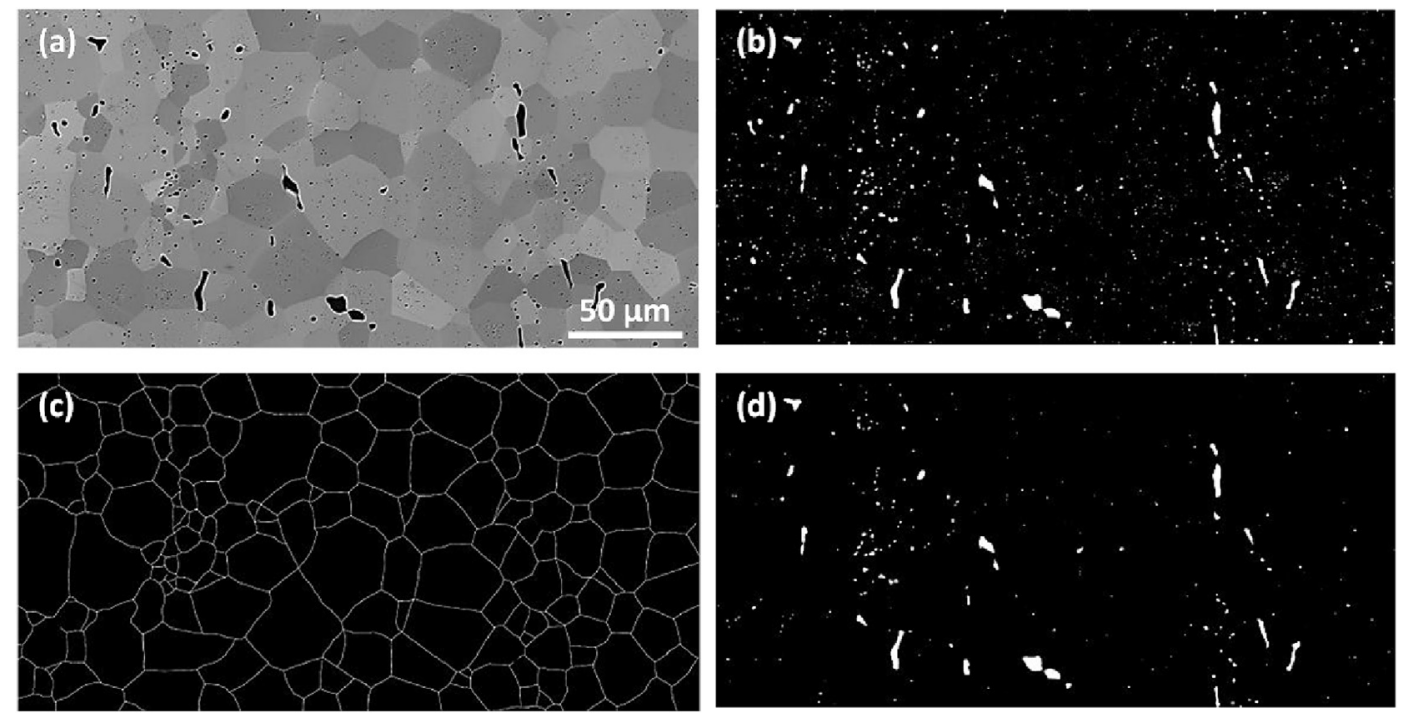

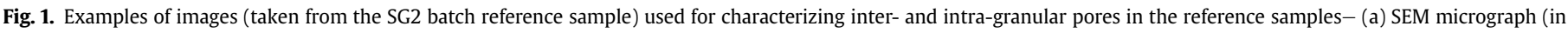
back-scattered electrons mode), (b) binarized image of the total porosity, (c) grain boundaries skeleton, (d) binarized image of the inter-granular porosity. 
pellets. EBSD maps performed on these samples allowed also to check the absence of sub-grain boundaries, within the grains (Fig. 2b). Indeed, very few boundaries with disorientations less than $5^{\circ}$ (white lines, some being pointed by arrows) were evidenced. They correspond in fact to scarce low angle grain boundaries with typical disorientations of the order of $2^{\circ}-5^{\circ}$.

Table 3 summarizes the characteristics of the fabrication porosity measured by image analysis of SEM images, in the assintered pellets. These results are given in terms of mean size $( \pm 20 \%)$ and surface density, for inter- and intra-granular pores. The total surface fraction corresponding to the whole measured porosity is also given. In the case of batches LG1 and LG2, this surface fraction is somewhat lower than expected from the density measurements (cf. Table 1), most likely due to a sampling effect and/or the small pores detection limit $(0.1 \mu \mathrm{m})$.

It is worth noting that the mean size of intra-granular pores is constant whatever the batch, whereas differences are observed concerning the mean size of inter-granular ones. In particular, the batch SG2 differs from the three others by an inter-granular pores average size approximately two times greater: this feature is consistent with batch SG2 lower density and is due to the use of a pore former during its fabrication.

Significant differences are also found between batches as regards the number of inter-/intra- granular pores per $\mathrm{mm}^{2}$. Indeed, the LG1 batch differs from the LG2 one by a lower interand, chiefly, intra-granular pores population (by almost 50\%). The intra-granular porosity of the SG1 batch is also significantly lower than that of the SG2 one, whereas their inter-granular porosity is similar and higher than that of LG1 and LG2 batches (as expected, given their smaller grain size). It is also interesting to note that LG2 and SG2 batches present very similar intra-granular pore populations.

In the case of LG1 and LG2 batches, prepared with the same powder, these differences are the consequence of different desagglomeration rates of the powder, before pressing, and different sintering conditions $\left(1900^{\circ} \mathrm{C}-4 \mathrm{~h}\right.$ for LG1 and $1900^{\circ} \mathrm{C}-10 \mathrm{~h}$ for LG2), as checked on several pellets from each batch and discussed in Refs. [15,23]. The SG1 and SG2 batches were sintered at a lower temperature than LG1 and LG2 batches $\left(1700{ }^{\circ} \mathrm{C}\right.$ instead of $1900{ }^{\circ} \mathrm{C}$ ), which led to their smaller grain size, their different pore populations being the consequence of the use of two different batches of powders (one of them being, moreover, mixed with a pore former).

\subsection{Microstructure of crept pellets}

Creep at $1500{ }^{\circ} \mathrm{C}$ produced two main changes in the microstructure on the four pellets: (i) the increase of inter-granular cavities, (ii) the development of sub-grain boundaries in the prior grains. Interestingly, the final density of inter-granular cavities and sub-grain boundaries varied significantly depending on the sample.

Since pellets were cooled at a $30^{\circ} \mathrm{C} / \mathrm{min}$ rate, with only a low compression load (5 MPa), a potential evolution of the dislocations distribution during the cooling stage is to be assessed. As subboundaries similar to those we observe were also described by Dherbey et al. in pellets quenched under stress [11,16], it seems reasonable to assume that sub-structures were not significantly modified in our samples, during the cooling stage, and can thus be compared. An evolution of the statistically stored dislocations density, which is not addressed in this study, is however probable.

\subsubsection{Intergranular cavities analysis}

Fig. 3 gathers SEM micrographs taken from the most damaged area of each crept sample. It highlights major differences between samples, which seem to be correlated with their average deformation rate. Indeed, if inter-granular cavities are always globally elongated in a direction parallel to the compression axis, as already observed by other authors $[11,24]$, their morphology varies from one sample to the other.

Thus, SG1 sample (Fig. 3c), which is the one exhibiting the highest mean strain rate, presents many facetted inter-granular cavities (crack-like) probably formed consequently to a grain boundary sliding process [11,25,26]. The LG1 sample (Fig. 3a) deformed more slowly presents fewer facetted cavities coexisting with lenticular pores alignments on some grain boundaries (see arrows in the figure). This type of alignments, which would be the result of vacancies diffusion migration mechanisms during the creep test $[11,25,26]$, is also visible in Fig. $3 b$ (see arrows) on the sample from batch LG2, which crept even slower and exhibits almost no facetted cavities. Finally, in the sample from batch SG2 (Fig. 3d) characterized by the highest initial porosity and having the slowest deformation rate, almost no inter-granular cavities with facetted or lenticular morphologies seem to have developed.

\subsubsection{Sub-structures analysis}

All four samples developed during creep a pronounced grain sub-structure (sub-grain boundaries and sub-grains). This substructure, easily revealed by variations in grey levels within the prior grains in the BSE-SEM images (cf. Fig. 3), was extensively studied by EBSD.

Fig. 4 evidences, as an example, the numerous sub-boundaries formed within the prior grains during creep in the crept sample from LG1 batch. Some of them are only partly detected (they form broken white lines), as their disorientation is close to the EBSD detection threshold in the conditions of this study. Indeed, it is very likely that sub-boundaries with even lower disorientations than $0.5^{\circ}$ were also present, considering the numerous slight contrast variations, visible within the grains on BSE-SEM micrographs (cf. Fig. 3). A higher angular resolution of EBSD data would probably close some open disorientation lines in Fig. 4.

Fig. 5 quantifies the number of grain boundaries (disorientation $\geq 5^{\circ}$ ) and sub-grain boundaries (disorientation comprised between $0.5^{\circ}$ and $5^{\circ}$ ) for the four crept samples. It shows that the fraction of sub-boundaries formed during creep changed depending on the samples. Especially, LG1 and LG2 samples differed significantly: the LG2 one, with the highest number of

Table 3

Characteristics of the fabrication porosity for the studied batches.

\begin{tabular}{|c|c|c|c|c|c|}
\hline \multirow[t]{2}{*}{ Batch } & \multicolumn{2}{|c|}{ Pores mean size, in $\mathrm{ECD}^{\mathrm{a}}(\mu \mathrm{m})$} & \multicolumn{2}{|c|}{ Number of pores per $\mathrm{mm}^{2}$} & \multirow[t]{2}{*}{ Total surface fraction (\%) } \\
\hline & Inter-granular pores & Intra-granular pores & Inter-granular pores & Intra-granular pores & \\
\hline LG1 & 0.8 & 0.4 & 4253 & 36526 & 0.6 \\
\hline LG2 & 0.8 & 0.4 & 6322 & 62120 & 1.0 \\
\hline SG1 & 1.2 & 0.4 & 9074 & 43776 & 1.5 \\
\hline SG2 & 2.1 & 0.4 & 9484 & 62995 & 4.0 \\
\hline
\end{tabular}

a ECD: equivalent circular diameter, i.e. disk diameter of the same area as the pore 

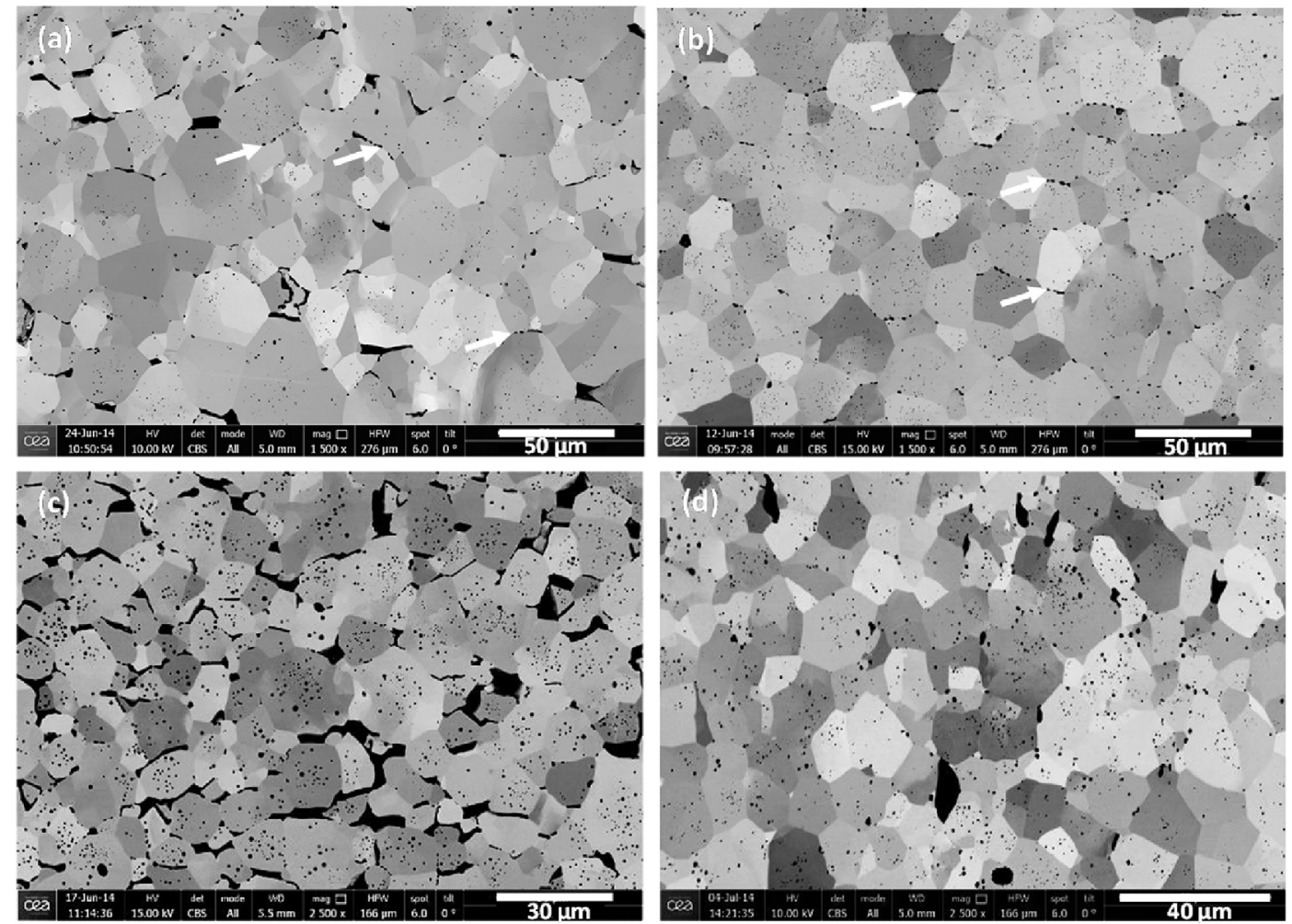

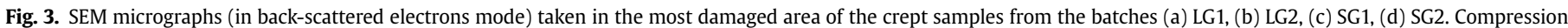
direction: horizontal.

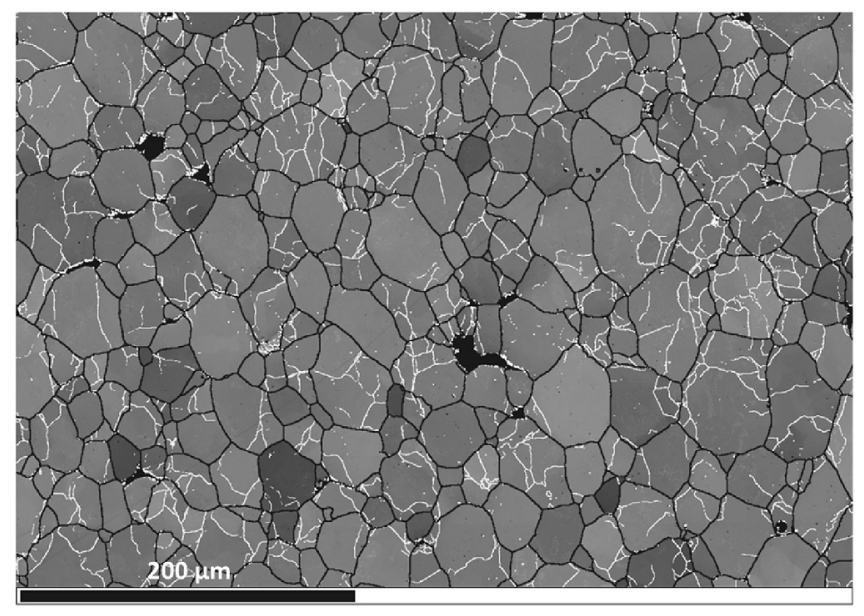

Fig. 4. Example of EBSD map obtained on the crept sample from the LG1 batch Kikuchi pattern quality map, grain boundaries (black lines: disorientation $\geq 5^{\circ}$ ) and sub-grain boundaries (white lines: disorientation comprised between $0.5^{\circ}$ and $5^{\circ}$ ) are superimposed.

pores within the prior grains, contained after creep ten times less sub-boundaries than the LG1 one. This result suggests that a higher fraction of intra-granular porosity, could reduce the stored fraction of geometrically necessary dislocations arranged in subboundaries.

In contrast, although the samples from the batches SG1 and SG2 had very different strain rates and exhibited cavities of very different morphologies, their grains contain substantially the same number of grain sub-boundaries (about 19\%). But one cannot exclude that different dislocations and cavities populations were

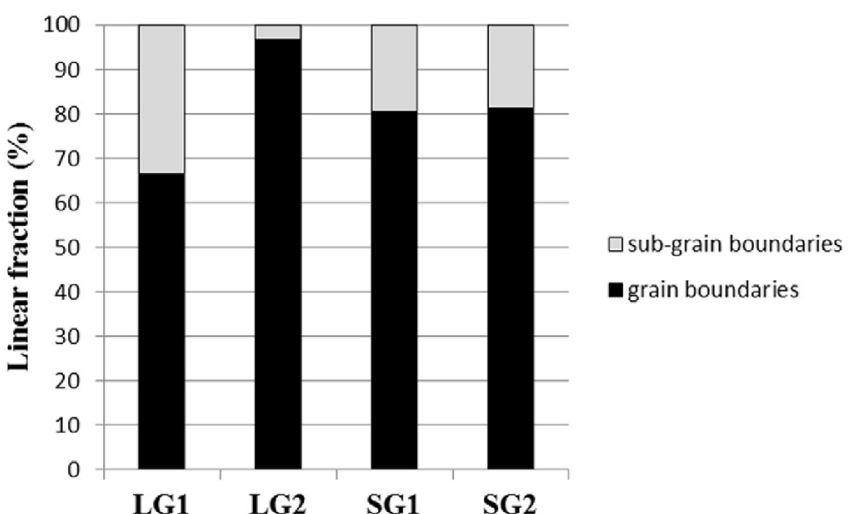

Fig. 5. Linear fraction of grain and sub-grain boundaries, measured by EBSD in the crept samples of the four studied batches.

present in each sample, at previous stages of the creep process, and evolved over time.

\section{Discussion}

In the previous section, four $\mathrm{UO}_{2}$ pellets batches were compared in terms of:

- fabrication porosity after sintering, and especially number of inter- and intra-granular pores,

- creep strain rate and creep damage, evidenced by the development of inter-granular cavities and sub-grain boundaries.

In particular, EBSD maps acquired on relatively large areas were 
post-processed to quantify the sub-boundaries linear fraction in each crept sample. This type of information is new, compared to those deducted from local examinations on thin sections by TEM, and could be worth for studying dislocational creep mechanisms and their link with the as fabricated $\mathrm{UO}_{2}$ microstructure.

Indeed, the comparison of the samples pointed out interesting tendencies:

- the pellets which had the lowest strain rates were those from the batches LG2 and SG2, which were also those having the largest number of intra-granular pores, regardless of their grain size (as expected for $\mathrm{UO}_{2}$ dislocational creep [7,11,15-17]),

- these pellets did not exhibit facetted cavities and had a small population of sub-grain boundaries, compared to those from the LG1 and SG1 batches, which had less numerous intra-granular pores and a higher creep strain rate.

Even if these conclusions are based on a limited sampling, they tend to indicate that there would exist interdependent relationships, in $\mathrm{UO}_{2}$ dislocational creep, between (i) the pores population (especially intra-granular pores), (ii) the trend for dislocations to organize themselves to form sub-grain boundaries and (iii) the strain rate. There is little information in the literature about the role of pores in the $\mathrm{UO}_{2}$ creep processes, at the microstructural scale. Porosity is generally taken into account as an adjustment parameter, in empirical creep laws [27] or treated as voids in mechanical simulations $[28,29]$. It is basically the same for technical ceramics.

Knowing that the creep mechanisms of $\mathrm{UO}_{2}$ are also likely to be affected by parameters such as the deviation from the stoichiometry [30,31] and/or impurities [32] or dopants [33], the manufacturing history of the different batches is also a factor to be taken into consideration in this discussion.

As the LG1, LG2 and SG1 pellets batches were manufactured in the same laboratory from the same starting powder, one can reasonably assume that they have the same impurities and the same stoichiometry. However, the SG2 batch has a different origin and a significantly higher total porosity. This porosity could also contribute to a partial accommodation of the deformation by closing the largest pores (i.e. the inter-granular ones), as it was noticed by Salvo et al. after compression tests on $\mathrm{UO}_{2}$ pellets at high strain rates [18]. That is perhaps the reason why no inter-granular cavities were observed in the SG2 crept sample. Comparing the first three ones allows identifying the following trends:

- LG1 and SG1 batches are characterized by similar intra-granular pores populations and a similar behavior during creep tests, i.e. a relatively high deformation rate associated with the development of facetted cavities, at grain boundaries, and of numerous sub-boundaries within the grains.

- Batch LG2, in which the intra-granular pores are much more numerous, has a slower deformation rate, forms relatively few sub-grains and develops small lenticular cavities at grain boundaries.

The particular behavior of this batch is at least also partially encountered in batch SG2, which also presents numerous intragranular pores.

These results tend to indicate that the intra-granular pores could play an important role in the viscoplastic deformation mechanisms of $\mathrm{UO}_{2}$. As an increase in the intra-granular pores number is associated with a decrease of the sub-grain boundaries number, it is likely that they could disturb the dislocations mobility and their reorganization into sub-boundaries, since it involves relatively complex gliding mechanisms [11,13,34]. Another mechanism involving these pores could be a local relaxation effect on the defects present within the grains, leading to a reduction of the deformation incompatibilities, and thus a decrease in the number of sub-grains. Moreover, one cannot exclude that these two hypothetical mechanisms may come into play concomitantly. Finally, grain size may also play a role in these processes. Indeed, large grains could be favorable to a high level of sub-structuration (case of LG1 batch), whereas smaller ones (case of SG1 batch) would be earlier saturated in sub-boundaries, promoting then grain boundaries sliding mechanisms, leading to numerous facetted cavities.

In order to try to get clues about the behavior of free dislocations and sub-boundaries close to pores, the observation of dislocations by electron channeling contrast imaging (ECCI) was applied prospectively on the crept sample from the LG1 batch.

Fig. 6 gives an example of a SEM image acquired in electrons channeling conditions (ECCI mode), on the crept sample from LG1 batch, according to the method described in Refs. [19,21,22]. On this image, small clear lines can be clearly distinguished within the grains: these lines reveal free dislocations (pointed by black arrows), as well as sub-grain boundaries (pointed by white arrows). Some of these sub-grains seem to be "pinned" at pores, as the one encircled by a white dotted line on the image.

This ECCI technique, implemented in a SEM on a bulk sample, appears thus to be well suited for studying sub-grain boundaries and dislocations and their interactions with pores in crept $\mathrm{UO}_{2}$ samples. ECCI images can also be compared to EBSD disorientation maps, taken in the same area, to distinguish and quantify the statistically stored dislocations and the geometrically necessary ones. Finally, coupling EBSD and ECCI should allow understanding better the viscoplastic deformation mechanisms in $\mathrm{UO}_{2}$ and their links with the original microstructural features of the ceramic and the solicitation conditions.

\section{Conclusion and prospects}

Four batches of $\mathrm{UO}_{2}$ pellets were studied comparatively, before and after creep tests, to evaluate a characterization methodology aimed to determine the links between microstructure and damage mechanisms induced by compressive creep of uranium dioxide at $1500{ }^{\circ} \mathrm{C}$. These batches were characterized, in the as sintered state, in order to determine, in particular, the characteristics of inter- and intra-granular pores (size, density and surface fraction). Samples from each batch were submitted to compression creep tests at $1500{ }^{\circ} \mathrm{C}$, at stress values chosen to activate dislocational creep

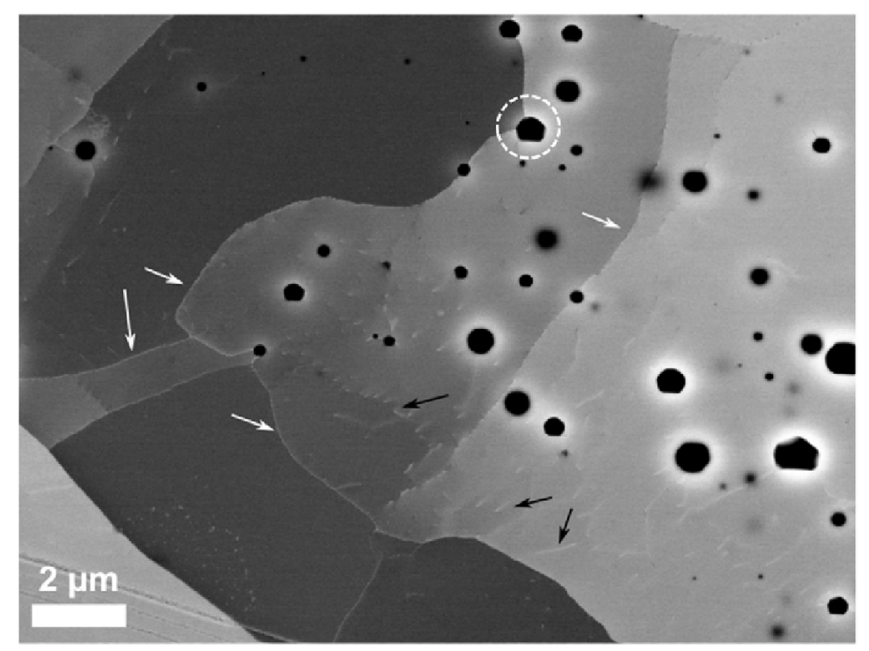

Fig. 6. SEM micrograph (in back-scattered electrons mode) taken in electrons channeling conditions on the crept sample of the LG1 batch. 
mechanisms, to mean deformation levels of the order of $8 \%$.

The examination of crept samples evidenced the formation of two different types of inter-granular cavities: relatively large facetted ones, predominating in samples characterized by high creep rates and smaller lenticular ones, mainly present in samples exhibiting lower strain rates. These two morphologies probably correspond to deformation mechanisms mainly driven by grain boundary sliding or diffusion processes (respectively). Thanks to EBSD maps, differences concerning the number of sub-grain boundaries present within grains were also identified: these subgrains were more numerous in the two samples with a relatively small population of intra-granular pores than in the other (carefully considering the case of batch SG2, which had a higher total porosity than the three other batches and had a partially specific behavior). Thus, intra-granular pores could play an important role in the $\mathrm{UO}_{2}$ visco-plastic deformation mechanisms. Different mechanisms potentially concomitant could be involved in this role, such as (i) a pinning effect of pores affecting dislocations mobility and dynamic recovery processes, (ii) a relaxation effect of pores on defects present within the grains, limiting deformation incompatibilities and, thus, sub-grains formation. A grain size effect, resulting in competition between dislocational creep and sub-structuration, within the grains, and grain boundaries sliding, could also come into play.

Conclusions previously drawn about the link between the intragranular pores number and the deformation rate need to be consolidated, given the small number of samples studied and the heterogeneity of the deformation at the pellet scale. Assumptions concerning the mechanisms involved in this interdependency also need to be checked on the basis of careful microstructural examinations.

These first results clearly illustrate the benefit of systematic examinations of crept $\mathrm{UO}_{2}$ pellets at a mesoscopic scale, by SEM and EBSD, to study their deformation process. In particular, quantified data concerning the grain sub-structuration process can be obtained by EBSD. In addition, prospective examination by ECCI performed on one of the crept samples led to very encouraging results, since this method appeared well suited to detect subboundaries and free dislocations within the grains and to image their interactions with the fabrication pores, in bulk samples.

\section{Acknowledgments}

The authors warmly thank the following people, from CEA/ Cadarache: E. Bertrand, for manufacturing some of the samples, J.P. Alessandri and M. Salvo, for performing creep tests, J. Sanchez for metallographic preparations, and $\mathrm{H}$. Rouquette and N. Tarisien for
SEM examinations and EBSD analyses. They also thank Z. El Omari, who contributed to this study during his Masters internship.

\section{References}

[1] S. Aas, Nucl. Eng. Des. 21 (1972) 237-253.

[2] R. Källström, A.M. Alvarez, U. Engman, K. Lafchiev, G. Lysell, G. Zhou, I. Arimescu, A.M. Sicilia, Proceedings of the 2011 LWR Fuel Performance MeetingTopFuel, Chengdu, China, Sept. 11-14, 2011.

[3] A.V. Burukin, A.L. Izhutov, G.P. Kobylyansky, V.I. Kuznetsov, V.L. Molchanov, V.V. Novikov, V.A. Ovchinnikov, Y.V. Pimenov, V.A. Zhitelev, Proceedings of the 2013 LWR Fuel Performance Meeting TopFuel, Charlotte, North Carolina, Sept. 15-19, 2013.

[4] B. Michel, J. Sercombe, C. Nonon, O. Fandeur, Compr. Nucl. Mater. 3 (2012) $677-712$.

[5] G. Khvostov, W. Lyon, M.A. Zimmermann, Ann. Nucl. Energy 62 (2013) $398-412$.

[6] J. Sercombe, R. Masson, T. Helfer, Nucl. Eng. Des. 260 (2013) 175-187.

[7] M.S. Seltzer, J.S. Perrin, A.H. Clauer, B.A. Wilcox, React. Tech. 14 (1971) 99-135.

[8] Y. Guérin, J. Nucl. Mater. 56 (1975) 61-75.

[9] D.B. Knorr, R.M. Cannon, R.L. Coble, Acta metall. 37 (1989) 2103-2123.

[10] B. Burton, G.L. Reynolds, J.P. Barnes, J. Mater. Sci. 8 (1973) 1690-1694.

[11] F. Dherbey, F. Louchet, A. Mocellin, S. Leclercq, Acta Mater. 50 (2002) 1495-1505.

[12] J.C. Gao, L.F. Wang, Y. Wang, S.F. Wu, Trans. Nonferrous Met. Soc. China 20 (2010) 238-242.

[13] C.S. Yust, J.T.A. Roberts, J. Nucl. Mater. 48 (1973) 317-329.

[14] X. Iltis, N. Gey, C. Cagna, A. Hazotte, Ph Sornay, J. Nucl. Mater. 456 (2015) 426-435.

[15] A. Ndiaye, PhD Thesis, University of Grenoble, France, 2012.

[16] F. Dherbey, PhD thesis, National Polytechnic Institute of Grenoble, France, 2000.

[17] C. Vivant-Duguay, PhD thesis, National Institute of Applied Science, Lyon, France, 1998.

[18] M. Salvo, J. Sercombe, J.C. Ménard, J. Julien, T. Helfer, T. Désoyer, J. Nucl. Mater. 456 (2015) 54-67.

[19] J. Guyon, H. Mansour, N. Gey, M.A. Crimp, S. Chalal, N. Maloufi, Ultramicroscopy 149 (2015) 34-44.

[20] J. Soulacroix, B. Michel, J.M. Gatt, R. Kubler, L. Barrallier, Int. J. Plast. 62 (2014) $121-137$.

[21] H. Mansour, J. Guyon, M.A. Crimp, N. Gey, B. Beausir, N. Maloufi, Scr. Mater 84-85 (2014) 11-14.

[22] H. Mansour, M.A. Crimp, N. Gey, N. Maloufi, Scr. Mater. 109 (2015) 76-79.

[23] A. Ndiaye, J.M. Chaix, Ph Sornay, 2012 ANS Annual Meeting, June 24-28, (Chicago, IL, USA).

[24] G.L. Reynolds, B. Burton, M.V. Speight, Acta Metall. 23 (1975) 573-577.

[25] C.R. Blanchard, K.S. Chan, J. Am. Ceram. Soc. 76 (1993) 1651-1660.

[26] J.R. Porter, W. Blumenthal, A.G. Evans, Acta Met. 29 (1981) 1899-1906.

[27] P.E. Bohaboy, R.R. Asamoto, A.E. Conti, USAEP Report N GEAP-10054, General Electric Company, 1969.

[28] Y. Monerie, J.M. Gatt, Mech. Mater. 38 (2006) 608-619.

[29] P.G. Vincent, Y. Monerie, P. Suquet, C.R. Mec. 336 (2008) 245-259.

[30] W.M. Armstrong, W.R. Irvine, J. Nucl. Mater. 2 (1963) 121-127.

[31] M.S. Seltzer, A.H. Clauer, B.A. Wilcox, J. Nucl. Mater. 44 (1972) 43-56.

[32] A.A. Solomon, C.S. Yust, N.H. Packan, J. Nucl. Mater. 110 (1982) 333-342.

[33] K.W. Kang, J.H. Yang, J.H. Kim, Y.W. Rhee, D.J. Kim, K.S. Kim, K.W. Song, J. Nucl. Sc. Tech. 47 (2010) 304-307.

[34] A.J. Forty, Discuss. Faraday Soc. 38 (1964) 56-60. 